\title{
SIPHONARIA (PULMONATE LIMPET) SURVEY OF JAPAN -II. PERIODICITY OF SPAWNING ACTIVITY IN SIPHONARIA JAPONICA-
}

\section{$\operatorname{AUTHOR}(\mathrm{S}):$}

Hirano, Yoshiaki

\section{CITATION:}

Hirano, Yoshiaki. SIPHONARIA (PULMONATE LIMPET) SURVEY OF JAPAN -II. PERIODICITY OF SPAWNING ACTIVITY IN SIPHONARIA JAPONICA-. PUBLICATIONS OF THE SETO MARINE BIOLOGICAL LABORATORY 1980, 25(5-6): 335-342

\section{ISSUE DATE:}

1980-11-15

URL:

http://hdl.handle.net/2433/176006

RIGHT: 


\title{
SIPHONARIA (PULMONATE LIMPET) SURVEY OF JAPAN \\ II. PERIODIGITY OF SPAWNING ACTIVITY IN SIPHONARIA JAPONICA ${ }^{1)}$
}

\author{
Yoshiaki HIRANO \\ Mukaishima Marine Biological Station, Faculty of Science, Hiroshima University, \\ Onomichi P.O., 722, Japan
}

With Text-figures $1-5$ and Tables $1-2$

\section{Introduction}

Breeding activities of various marine pulmonates have been investigated, e.g., Siphonaria pectinata by Voss (1959) and Zischke (1974), Melampus bidentatus by RussellHunter et al. (1972), Siphonaria alternata by Zischke (1974), etc. Other papers are summarized by Berry (1977). He has pointed out that breeding is limited to particular seasons in several cases. Siphonaria japonica (Donovan, 1824) is the most common pulmonate limpet on Japanese rocky intertidal shores. Members of this species lay their eggs in semi-circular or nearly circular ribbons on rock surfaces. A previous paper dealt cheifly with the activity of movement and mating behavior of this species during its springtime breeding season (Hirano and Inaba, 1980).

Continuing this work, the primary aim of the present study was to investigate spawning activity in detail and to see if relationships exist between this activity and environmental conditions. Although Abe (1940) has already described spawning periodicity in S. japonica, a very different result could be obtained in this study by counting carefully the number of egg ribbons every day. In addition, by comparing our results with those of Abe's study, the range of sea water temperatures associated with spawning of $S$. japonica has also been reexamined in relation to the difference between localities.

\section{Material and Methods}

The field study was conducted on a boulder-dominated intertidal shore of Matsugahana neighboring the Mukaishima Marine Biological Station, Mukaishima Island $\left(34^{\circ} 22^{\prime} \mathrm{N}: 133^{\circ} 14^{\prime} \mathrm{E}\right)$, northwest of Bingonada, Seto Inland Sea of Japan. Egg ribbons of Siphonaria japonica laid on one small rock surface (Fig. 1) were entirely removed with a pincette and a knife and were counted every day from February 22 to June 26, 1978, in order to know the number of newly laid ribbons on the consec-

1) Contribution from the Mukaishima Marine Biological Station. No. 178.

Publ. Seto Mar. Biol. Lab., XXV (5/6), 335-342, $1980 \quad$ (Article 21) 


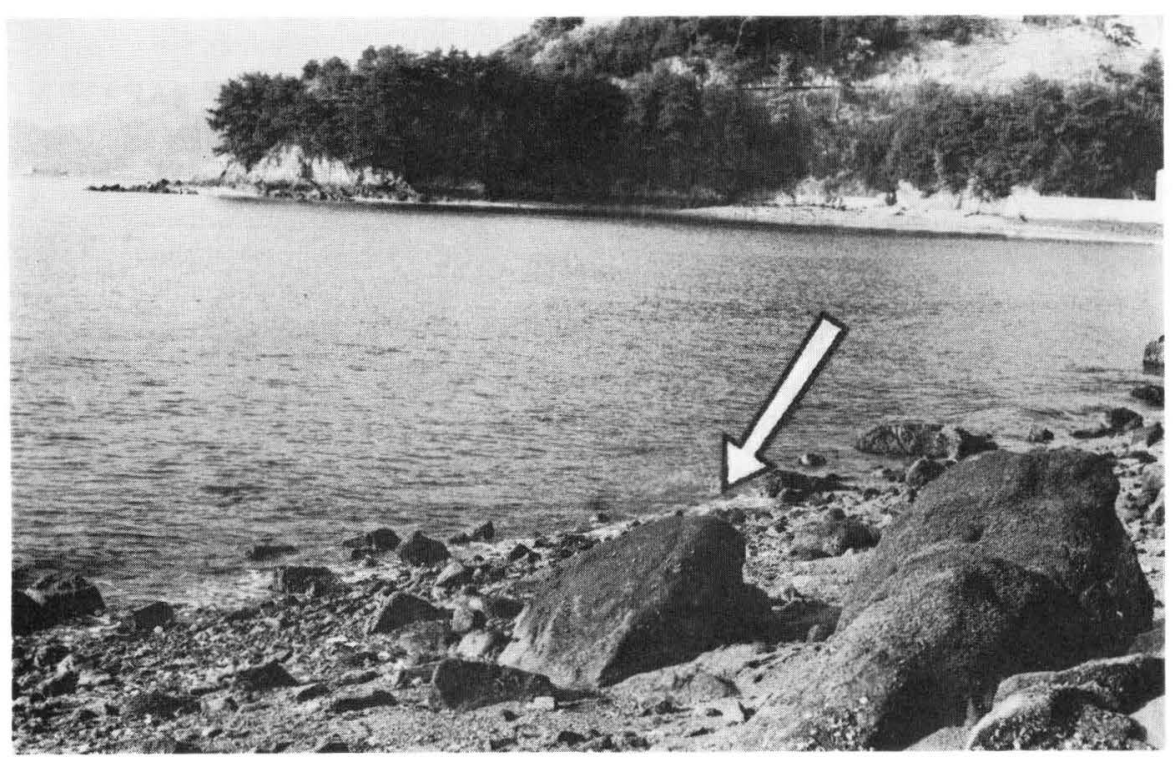

Fig. 1. A small rock where the egg ribbons of $S$. japonica were removed. The length of its longest side is about $160 \mathrm{~cm}$ and its height about $85 \mathrm{~cm}$.

tive days. The small rock was situated at about $170 \mathrm{~cm}$ above tidal datum. At this site, the tidal level was almost at the center of the zonal distribution of S. japonica. No egg ribbons were detected on the rock before March 11 except for three egg rib-

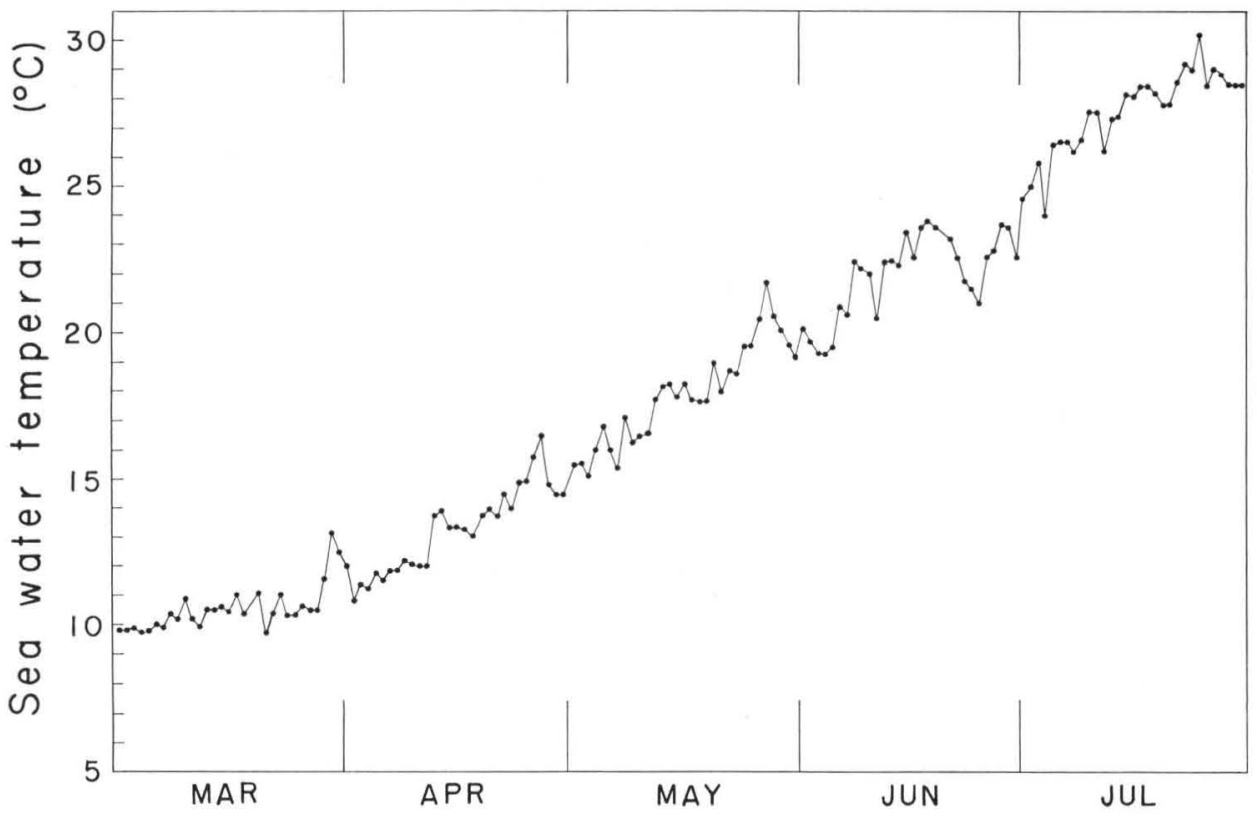

Fig. 2. Changes in sea water temperature from March to July, 1978, at an investigated site off Mukaishima Island. 
bons observed on March 2 on other rocks, which was the first record of 1978 for the author in Mukaishima Island.

Since a rock that was isolated from surrounding rocks by a sandy area was chosen, it was assumed that no emigration from or immigration to the population occurred. At the beginning of the observation, 137 adult individuals were recognized in all. Their numbers were also recorded on subsequent occasions to examine the spawning ability per individual. The sea water temperatures during the period of the study are shown in Fig. 2 which was constructed from data given in Hoshino and Katayama (1979).

\section{Results}

The number of egg ribbons which were laid each day on the rock surface changed as shown in Fig. 3. The waxing and waning of the moon are also shown using the conventional representation. (Data were not collected during the period from April 1 to 9 due to logistical difficulties.) A total of $410 \mathrm{egg}$ ribbons were removed from the rock and counted during the present study. Peaks and troughs at more or less regular intervals are apparent and indicate a periodicity in the spawning activity of Siphonaria japonica. In order to examine this trend more closely, the number of egg ribbons laid is matched against lunar phase in Table 1. From this it is evident that the number of egg ribbons differed with different periods: High spawning activity always occurred during the second and fourth quarters of the moon, whereas light activity coincided with the first and third quarters.

Fig. 4 represents changes in the number of parental individuals during this study. The decreasing numbers are not caused by emigration from the rock but by death since no migration off of or on the rock was possible. The actual spawning

Table 1. Relationship between the number of egg ribbons laid $(\mathrm{N})$ and lunar phase.

\begin{tabular}{|c|c|c|c|}
\hline$\frac{0 \rightarrow 0}{0 \rightarrow 0}$ & $\mathrm{~N}$ & $\begin{array}{l}0 \rightarrow 0 \\
0 \rightarrow 0\end{array}$ & $\mathrm{~N}$ \\
\hline$\frac{3 / 9-3 / 16}{3 / 25-3 / 31}$ & $\begin{array}{l}10 \\
17\end{array}$ & $\frac{3 / 17-3 / 24}{4 / 1-4 / 7}$ & $\frac{24}{?}$ \\
\hline$\frac{4 / 8-4 / 14}{4 / 23-4 / 29}$ & $\frac{?}{25}$ & $\frac{4 / 15-4 / 22}{4 / 30-5 / 6}$ & $\frac{70}{62}$ \\
\hline$\frac{5 / 7-5 / 14}{5 / 22-5 / 28}$ & $\begin{array}{r}11 \\
4\end{array}$ & $\begin{array}{l}5 / 15-5 / 21 \\
5 / 29-6 / 5\end{array}$ & $\begin{array}{l}60 \\
31\end{array}$ \\
\hline $6 / 6-6 / 13$ & 9 & $6 / 14-6 / 20$ & 20 \\
\hline total & 76 & & 267 \\
\hline mean & 12.7 & & 44.5 \\
\hline S.D. & \pm 6.7 & & $=20.0$ \\
\hline
\end{tabular}

Differerence between mean number $( \pm$ S.D.) of egg ribbons was significant $(\mathrm{p}<0.02)$. From April 1 to $14,59 \mathrm{egg}$ ribbons were counted in all. From June 21 to 26,5 egg ribbons were counted. 


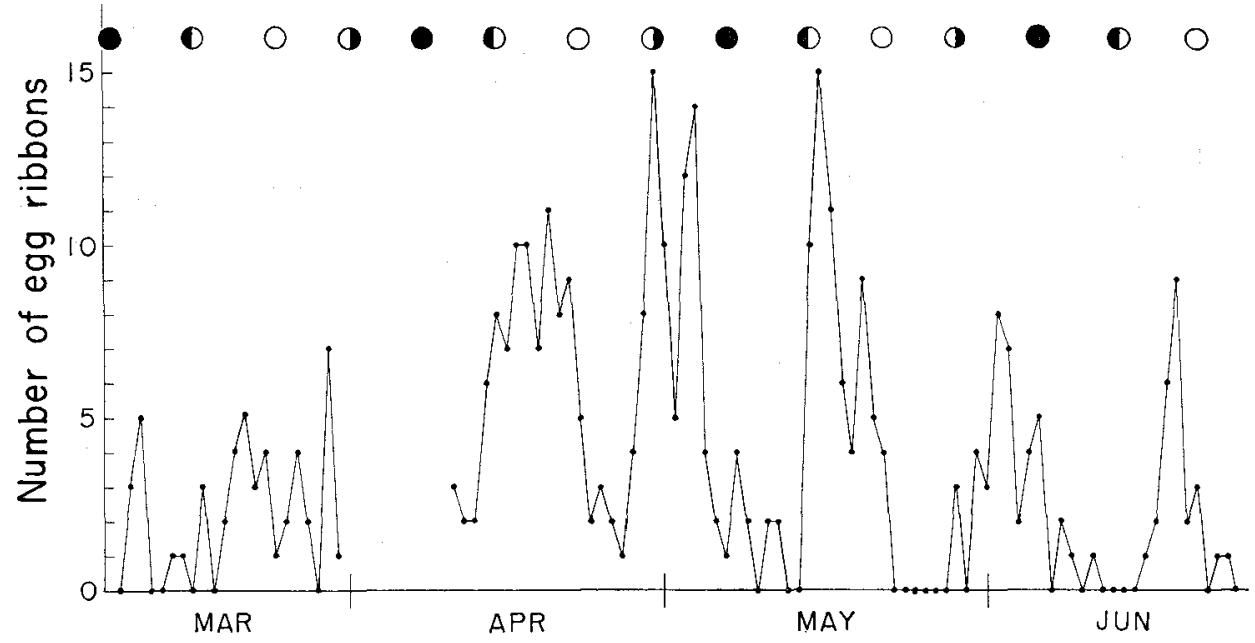

Fig. 3. Changes in the number of $S$. japonica egg ribbons deposited on the rock surface. (From March 10 to June 25)

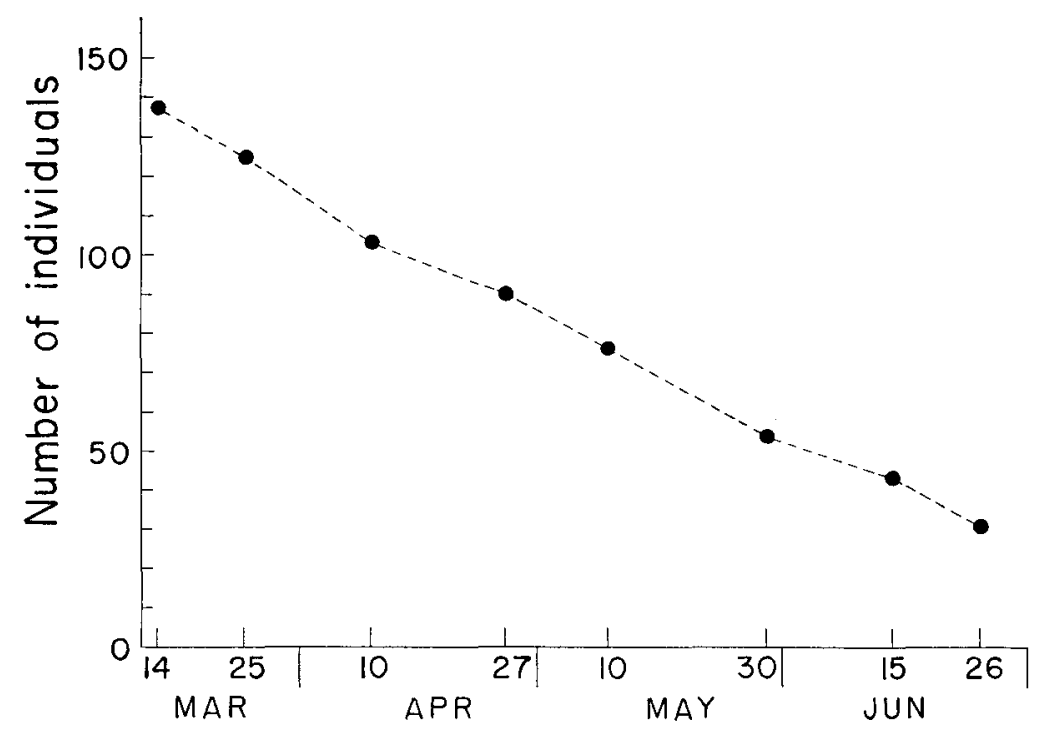

Fig. 4. Changes in the number of individuals of $S$. japonica on the rock surface throughout the course of the study.

output per individual during a certain period should be determined from the ratio of egg ribbons to individuals. Based on Fig. 4 and Table 1, the number of parental individuals and the average output of egg ribbons per individual during each period are shown in Table 2. From this table, the most active period of spawning is seen to be from approximately May 15 to 21 (ca. 0.90 egg ribbons per individual), in spite of the fact that the greatest number of egg ribbons (70) was counted during the period 
Table 2. Number of parental individuals and spawning output per individual during each period

\begin{tabular}{ccc}
\hline \hline & parents & egg ribbons \\
\hline $3 / 9-3 / 16$ & 137 & 0.07 \\
$3 / 17-3 / 24$ & 130 & 0.18 \\
$3 / 25-3 / 31$ & 211 & 0.14 \\
$4 / 1-4 / 7$ & 111 & $?$ \\
$4 / 8-4 / 14$ & 103 & $?$ \\
$4 / 15-4 / 22$ & 97 & 0.72 \\
$4 / 23-4 / 29$ & 91 & 0.27 \\
$4 / 30-5 / 6$ & 84 & 0.74 \\
$5 / 7-5 / 14$ & 75 & 0.15 \\
$5 / 15-5 / 21$ & 67 & $* 0.90$ \\
$5 / 22-5 / 28$ & 60 & 0.07 \\
$5 / 29-6 / 5$ & 53 & 0.58 \\
$6 / 6-6 / 13$ & 47 & 0.19 \\
$6 / 14-6 / 20$ & 40 & 0.50 \\
\hline
\end{tabular}

from April 15 to 22 (see Table 1). By consulting Fig. 2, we see that this period of high egg output occurred at about $18^{\circ} \mathrm{C}$ water temperature. Therefore, this temperature appears to be the optimum one for spawning in $S$. japonica. Judging from the first record of egg ribbons on the sampled rock, the spawning season of $S$. japonica at Mukaishima Island is considered to begin from the middle of March, when the sea water temperature is about $10-11^{\circ} \mathrm{C}$. Although the time of final spawning could not be ascertained exactly, it is probably about the middle of July at the latest (When sea water temperature is about $27^{\circ} \mathrm{C}$ ) because additional newly laid egg ribbons were not detected late in July. The optimum temperature $\left(18^{\circ} \mathrm{C}\right)$ is apparently just midway between the upper and lower limits for spawning activity.

Concerning the time of spawning, activity was not observed during daytime but mainly at night.

\section{Discussion}

By continuously removing newly laid egg ribbons from a fixed study area (one boulder) and counting their number, it has been demonstrated that there is a quite marked periodicity of spawning activity in Siphonaria japonica at Mukaishima Island (Fig. 3 and Table 1). Similar cycles of egg laying which are related to lunar phases or tidal cycles have been reported in other pulmonate molluscs although their intervals are different according to species. Zischke (1974) found that fluctuations in the number of deposited egg masses of Siphonaria pectinata were roughly related to the tidal cycle with the highest deposition occurring during spring tides. (He also kept a record of spawning in Siphonaria alternata, but because of an inadequate number of counts, no clear correlation between egg laying periodicity in $S$. alternata and the 
tidal cycle could be determined.) In his study, the time-relationship between mating and spawning of $S$. pectinata was not investigated.

There are, however, some studies which have dealt with these points. Studying the salt-marsh pulmonate snail, Melampus bidentatus, Russell-Hunter et al. (1972) reported that semilunar syncrony was obligate in not only egg-laying but also in aggregation and copulation. According to them, all these processes occur at twoweek intervals in phase with the tides of new and full moon; aggregation and copulation just slightly precede egg-laying. For the same species as used in the present study, Siphonaria japonica, Abe (1940) concluded from his observations at Asamushi (40 $54^{\prime} \mathrm{N}$ : $\left.140^{\circ} 52^{\prime} \mathrm{E}\right)$, Aomori Prefecture, northern Japan, that spawning occurs only at the time of the full moon. He also reported that mating in $S$. japonica takes place or begins to take place mainly at the time of the waxing half moon and that spawning occurs about seven days after mating (just at the time of the full moon).

It has been recently reported, however, that such a clear periodicity of mating activity in S. japonica was not found at Mukaishima Island; almost the same proportion of copulating individuals were observed at every lunar phase (Hirano and Inaba, 1980). How, then, can the spawning periodicity at Mukaishima be explained? Hirano and Inaba (op. cit.) revealed that greater activity of movement of $S$. japonica occurred during the night than in the daytime but that mating was not necessarily restricted to night. Active spawning behavior, however, was observed under dark conditions or night during entire course of this study. Since shifts in the time of movement simply follow shifts in the tide (Hirano and Inaba, op. cit.), when they are compared with the different periods as shown in Table 1 or Table 2, it is found that the periods of low spawning activity always seem to correspond to the periods of little nighttime movement (Fig.5). That is to say, the spawning periodicity observed in the present study is probably correlated with the amount of nighttime movement rather than changes of mating activity prior to egg laying. Differences between the localities may possibly explain differences in the periodicity of spawning. Reinvestigation of spawning at Asamushi and additional investigations at other places using the same technique as in this study would be welcome in order to determine whether spawning periodicity in $S$. japonica does indeed change with locality and what factors actually determine the periodicity.

Abe (1940) also reported that the spawning season in $S$. japonica takes place during the months of May, June and July at Asamushi, where the sea water temperature ranges from $13^{\circ}$ to $23^{\circ} \mathrm{C}$. The present author observed a quite high spawning activity of the species at Amakusa Islands $\left(32^{\circ} 25^{\prime} \mathrm{N}: 130^{\circ} 0^{\prime} \mathrm{E}\right)$, Kumamoto Prefecture, southern Japan, on January 29, 1978, when the sea water temperature was about $12^{\circ} \mathrm{C}$. The present observations show that $S$. japonica spawned from the middle of March, when the sea water temperature was $10-11^{\circ} \mathrm{C}$, to middle July, when the sea water temperature was $27^{\circ} \mathrm{C}$. These facts suggest that the spawning season of $S$. japonica is chiefly dependent upon sea water temperature and begins earlier in southern latitudes than in more northern ones. Furthermore, the range of 


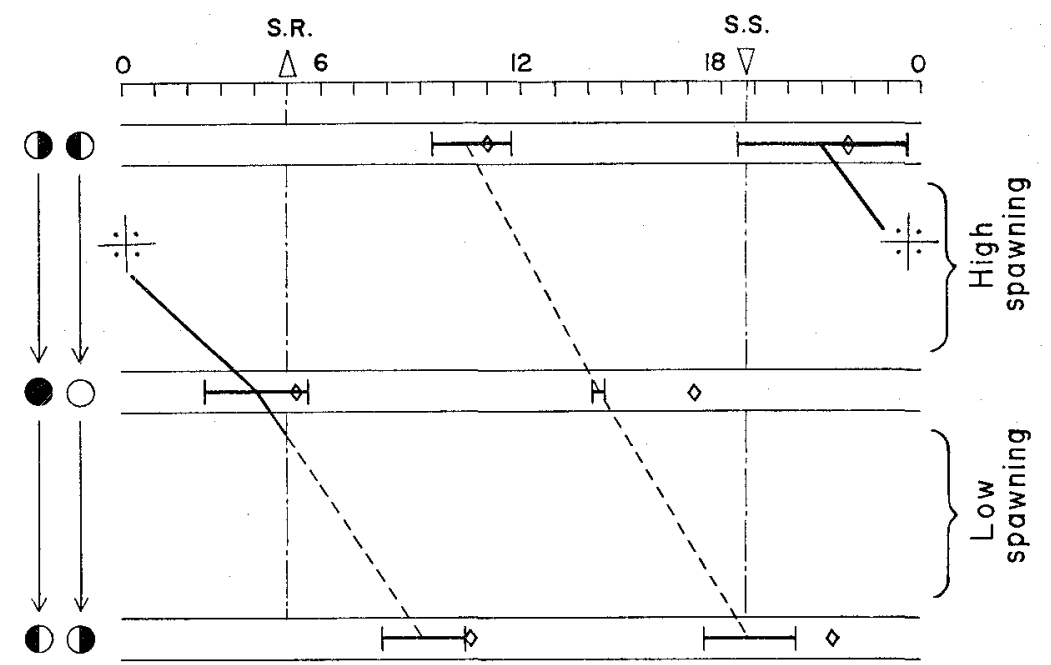

Fig. 5. Changes in the time of movement (horizontal bar $|-|$ ) with tidal phase. Solid lines connected between the horizontal bars represent the series of times of movement during night. Dotted ones represent those of daytime movement. Therefore, the periods from half to new or full moon have one nighttime movement at least $(-0,0-\bigcirc)$. The remaining quartes have little nighttime movement $(\mathbf{O}, \mathrm{O}-\mathbf{O})$. This relation is invariable at Mukaishima Island. $\diamond$ : Low tide. S.R.: Sunrise, S.S.: Sunset.

sea water temperature which is adequate for spawning of $S$. japonica may be said to be slightly wider than previously estimated by Abe.

Some different results have also been reported on the spawning period of the other siphonariid limpets. For example, Voss (1959) reported that Siphonaria pectinata spawned only from December through March when sea water temperature was $21^{\circ}$ to $23^{\circ} \mathrm{C}$. On the other hand, Zischke (1974) reported that S. pectinata spawned from late September to early May $\left(28.3^{\circ}\right.$ to $\left.24.4^{\circ} \mathrm{C}\right)$. Because both investigations were carried out in southern Florida, $S$. pectinata seems to have a relatively wide flexibility in the temperature range over which spawning occurs. In contrast, it may be said that $S$. japonica spawns over a relatively constant temperature range even in geographically distant localities.

\section{Acknowledgement}

The author is deeply indebted to Prof. A. Inaba of the Mukaishima Marine Biological Station, for his encouragement and critical advice. Mr. R.B. Gillmor of the University of Maine kindly read the manuscript, to whom the author's thanks are due.

\section{Summary}

1) Spawning activity of the pulmonate limpet Siphonaria japonica (Donovan, 1824) was investigated by continuously removing its egg ribbons and counting their number. 
2) A quite marked periodicity of spawning activity in $S$. japonica was observed. High activity always occurred during the second and fourth quarters of the moon; spawning was slight during the first and third quarters.

3) It is assumed that the observed periodicity is correlated with shifts in the time of movement. Spawning activity is low during periods having little nighttime movement, but is high for periods during which the limpets are relatively active for part of each day.

4) The spawning period of S. japonica is estimated to be from the middle of March to the middle of July at Mukaishima Island, where the sea water temperature ranges from $10-11$ to $27^{\circ} \mathrm{C}$. The optimum temperature appears to be about $18^{\circ} \mathrm{C}$ (which occurred from May 15 to 21 in the present study).

5) By comparing data from various localities, the spawaning period seems to be chiefly a function of sea water temperature and begins later with increasing latitude.

\section{REFERENCES}

Abe, N. 1940. The homing, spawning and other habits of a limpet, Siphonaria japonica Donovan. Sci. Rep. Tohoku Imp. Univ., 4th Ser., (Biol.), Vol. 15, pp. 59-95.

Berry, A.J. 1977. Gastropoda: pulmonata. In "Reproduction of marine invertebrates", (A.C. Giese and J.S. Pearse, eds.), Vol. 4, Chapter 3, pp. 181-226, Academic Press, New York.

Hirano, Y and A. Inaba, 1980. Siphonaria (pulmonata limpet) survey of Japan. 1. Observations on the behavior of Siphonaria japonica during breeding season. Publ. Seto Mar. Biol. Lab., Vol. 25, pp. 323-334.

Hoshino, T. and H. Katayama, 1979. Some oceanographical and meteorogical conditions observed at a definite station off Mukaishima Marine Biological Station in 1978. Mukaishima Mar. Biol. Sta.

Russell-Hunter, W.D., M.L. Apley and R.D. Hunter, 1972. Early life-history of Melampus and the significance of semilunar syncrony. Biol. Bull., Vol. 143, pp 623-656.

Voss, N.A. 1959. Studies on the pulmonate gastropod Siphonaria pectinata (Linnaeus) from the southeast coast of Florida. Bull. mar. Sci., Gulf Caribb., Vol. 9, pp. 84-99.

Zischke, J.A. 1974. Spawning, development and growth in the pulmonate limpets Siphonaria pectinata L. and Siphonaria alternata Say. Veliger, Vol. 16, pp. 399-404. 